\title{
Confounding Factors Influencing Amyloid Beta Concentration in Cerebrospinal Fluid
}

\author{
Maria Bjerke, ${ }^{1}$ Erik Portelius, ${ }^{1}$ Lennart Minthon, ${ }^{2}$ Anders Wallin, ${ }^{1}$ \\ Henrik Anckarsäter, ${ }^{3}$ Rolf Anckarsäter, ${ }^{3}$ Niels Andreasen, ${ }^{4,5}$ Henrik Zetterberg, ${ }^{1}$ \\ Ulf Andreasson, ${ }^{1}$ and Kaj Blennow ${ }^{1}$ \\ ${ }^{1}$ Department of Psychiatry and Neurochemistry, Institute of Neuroscience and Physiology, The Sahlgrenska Academy at \\ University of Gothenburg, 43180 Mölndal, Sweden \\ ${ }^{2}$ Department of Clinical Sciences Malmö, Clinical Memory Research Unit, Lund University, 20502 Malmö, Sweden \\ ${ }^{3}$ Forensic Psychiatry, Institute of Neuroscience and Psychology, The Sahlgrenska Academy at \\ University of Gothenburg, 42250 Gothenburg, Sweden \\ ${ }^{4}$ Department of Neurobiology, Karolinska Institute, Caring Sciences and Society, Karolinska University Hospital, \\ Huddinge, 14186 Stockholm, Sweden \\ ${ }^{5}$ Department of Geriatric Medicine, Karolinska Institute, Memory Clinic, M51, Karolinska University Hospital, \\ Huddinge, 14186 Stockholm, Sweden
}

Correspondence should be addressed to Maria Bjerke, maria.bjerke@neuro.gu.se

Received 15 March 2010; Accepted 7 June 2010

Academic Editor: Lucilla Parnetti

Copyright ( 2010 Maria Bjerke et al. This is an open access article distributed under the Creative Commons Attribution License, which permits unrestricted use, distribution, and reproduction in any medium, provided the original work is properly cited.

Background. Patients afflicted with Alzheimer's disease (AD) exhibit a decrease in the cerebrospinal fluid (CSF) concentration of the 42 amino acid form of $\beta$-amyloid $\left(\mathrm{A} \beta_{42}\right)$. However, a high discrepancy between different centers in measured $\mathrm{A} \beta_{42}$ levels reduces the utility of this biomarker as a diagnostic tool and in monitoring the effect of disease modifying drugs. Preanalytical and analytical confounding factors were examined with respect to their effect on the measured $\mathrm{A} \beta_{42}$ level. Methods. Aliquots of CSF samples were either treated differently prior to $A \beta_{42}$ measurement or analyzed using different commercially available xMAP or ELISA assays. Results. Confounding factors affecting CSF A $\beta_{42}$ levels were storage in different types of test tubes, dilution with detergent-containing buffer, plasma contamination, heat treatment, and the origin of the immunoassays used for quantification. Conclusion. In order to conduct multicenter studies, a standardized protocol to minimize preanalytical and analytical confounding factors is warranted.

\section{Introduction}

By the year of 2000, it was estimated that more than 25 million people suffered from dementia, with Alzheimer's disease (AD) being the most common subtype accounting for around 50 percent of all cases $[1,2]$. Histopathological hallmarks of $\mathrm{AD}$ include intracellular neurofibrillary tangles composed of tau protein and extracellular deposits of neurotoxic $\beta$-amyloid $(\mathrm{A} \beta)$ visualized as amyloid plaques [3-5]. The cerebrospinal fluid (CSF) concentrations of $\mathrm{A} \beta$ peptides in combination with the tau protein and its hyperphosphorylated forms have been found to support the clinical diagnosis of AD [6]. Not only do these biomarkers fulfill the criteria for an ideal diagnostic test according to the guidelines of the Working group on molecular and biochemical markers of Alzheimer's disease [7], but $A \beta$ have also been suggested to be a driving force in the disease process. The amyloid cascade hypothesis proposes that an imbalance in $\mathrm{A} \beta$ production and clearance leads to an increase in $A \beta$ load and that this initiates taupathology and neuronal degeneration which ultimately causes dementia [8]. The hypothesis is derived from cases affected by rare familial forms of $\mathrm{AD}$ wherein mutations in the amyloid precursor protein $(A P P)$ gene or in the presenilin-encoding (PSEN1 and PSEN2) genes, which are involved in metabolizing the APP protein, invariably lead to AD pathology. The 42 amino 
acid long form of $\mathrm{A} \beta\left(\mathrm{A} \beta_{42}\right)$ has also proven to be the best established CSF biomarker for amyloid pathology in the brain. $A \beta$ has therefore become the primary target of many clinical trials in their search for novel treatment strategies as well as a core biomarker candidate for monitoring diseasemodifying effects [9].

Recently a large multicenter study assessed the diagnostic value of the 42 amino acid long form of $\mathrm{A} \beta\left(\mathrm{A} \beta_{42}\right)$, total tau (T-tau), and tau phosphorylated at threonine 181 (P$\operatorname{tau}_{181}$ ) in identifying subjects with incipient $\mathrm{AD}$ among patients with mild cognitive impairment (MCI) and they were found to provide good accuracy [10]. The neuropathologic correlates distinguishing those of the MCI patients thought to await in the precedent stage of clinical overt $\mathrm{AD}$ [11], are seemingly reflected by these biomarkers. Although the biomarkers show reasonable accuracy to discriminate controls from $\mathrm{AD}$ patients as well as prodromal $\mathrm{AD}$ in $\mathrm{MCI}$ patients [12-15], it has been shown in population-based studies that healthy elderly people who later develop $\mathrm{AD}$ have reductions in CSF $\mathrm{A} \beta_{42}$ levels while tau levels are normal $[16,17]$. However, there is a high discrepancy in the reported concentrations of these biomarkers [18] leading to different cut-off values between different centers with the highest variability shown for $A \beta_{42}$ [10]. This type of between-center variability in analytical results may be due to differences in preanalytical procedures for CSF collection and sample processing, analytical procedures and techniques, and to batchto-batch variation for the immunoassay kits. It has been suggested that preanalytical confounding factors such as CSF collection, storage, and adsorption to tube-walls contribute to the highest magnitude of errors [19]. This paper aims at assessing these preanalytical confounding factors together with other factors such as blood contamination, blood-brain barrier dysfunction, sample pretreatment and differences in assay performance regarding the impact on measured $A \beta_{42}$ levels.

\section{Material and Methods}

2.1. CSF and Plasma Samples. All CSF samples were obtained by lumbar puncture (LP) between the L3/L4 and L4/L5 intervertebral space. Except when otherwise noted, a volume of 10-12 mL CSF was collected in polypropylene tubes followed by centrifugation $\left(2000 \times \mathrm{g}, 10 \mathrm{~min}, 4^{\circ} \mathrm{C}\right)$ and storage in smaller aliquots at $-80^{\circ} \mathrm{C}$. Plasma was obtained by the centrifugation $\left(2500 \times \mathrm{g}, 10 \mathrm{~min}, 4^{\circ} \mathrm{C}\right)$ of whole blood in EDTA tubes (BD, art. nr. 367864). The plasma was aliquoted into polypropylene tubes and stored at $-80^{\circ} \mathrm{C}$ pending analysis. All samples were thawed at room temperature (RT), if nothing else is declared. The samples used for evaluation of confounding factors were aliquots from samples sent for routine diagnostic purposes. All samples were decoded so that no information could be linked to an individual patient.

2.2. Subjects. Two case control studies assessed the differences in CSF $A \beta_{42}$ levels due to differences in pretreatment, the first study comprised $15 \mathrm{AD}$ and 15 control samples and the second comprised $20 \mathrm{AD}$ and 20 control samples.
The patients who received the diagnosis of $\mathrm{AD}$ fulfilled the DSM-III-R criteria of dementia [20] and the criteria of probable $\mathrm{AD}$ defined by NINCDS-ADRDA (National Institute of Neurological and Communicative DisordersStroke/Alzheimer's Disease and Related Disorders Association) [21]. Healthy controls were mainly recruited from senior citizens' organizations, while a few were spouses of study patients. Controls were not included if they had a history or subjective or objective signs of a cognitive disorder.

The study was conducted according to the provisions of the Helsinki Declaration and was approved by the ethics committee of the Universities of Gothenburg and Lund and the Karolinska Institute, Sweden.

2.3. CSF Analysis. Unless otherwise stated, the CSF $\mathrm{A} \beta_{42}$ concentrations were obtained using the Innogenetics NV INNO-BIA xMAP technology (INNO-BIA AlzBio3) [22]. For practical reasons some tests were analyzed using the established Innogenetics enzyme-linked immunosorbent assay (ELISA) (INNOTEST $\beta$-amyloid ${ }_{1-42}$ ) [23], using a slightly modified protocol [24], which has previously been shown to correlate well with the Innogenetics AlzBio3 assay [22]. Since preanalytical factors were to be assessed and not absolute $\mathrm{A} \beta_{42}$ levels, using different assays should pose no problems. In a case control study, these assays were compared with four other commercially available $A \beta_{42}$ immunoassays from Innogenetics (INNO-BIA plasma $\mathrm{A} \beta$ forms) [25], Meso-Scale Discovery (MSD 96-Well MULTI-SPOT, Human/Rodent (4G8) Abeta Triplex Ultra-Sensitive Assay) [26], and The Genetics Company (hAmyloid $\beta 42$ ELISA) $[27,28]$, to evaluate their performance in discriminating between $\mathrm{AD}$ patients and healthy controls. All analyses were performed according to manufacturers' instructions; however, the Innogenetics ELISA was also performed by replacing the detection antibody with the 4G8 monoclonal antibody. The capture and detection antibodies for each assay are summarized in Table 1 . Whenever practically possible the samples for a specific experiment were run on the same plate in order to eliminate errors caused by interassay variability.

2.4. Statistical Analysis. Since several variables were found to be skewed the nonparametric Friedman's or Wilcoxon tests were used for pairwise comparisons while the MannWhitney $U$-test was employed for unpaired comparisons. The data is presented as median and percentiles (5th and 95th). Correlation analyses were performed using the Spearman correlation coefficient (rho). Receiver operating characteristic (ROC) analyses were performed to evaluate the discrimination power of the different assays using the area under the curve (AUC). SPSS 15.0 was employed for all univariate analyses.

\subsection{Sample Collection and Assessment of Confounding Factors}

2.5.1. Adsorption to Test Tubes and Lumbar Catheter Walls. Freshly collected CSF from ten different subjects was tapped into glass (Schott, art. nr. 2317103), polypropylene (Sarstedt, art. nr. 60.549), and polystyrene (Sarstedt, art. nr. 55.476) 
TABle 1: Properties of evaluated commercially available A $\beta$ assays. The various capture and detection antibodies employed in the different $\mathrm{A} \beta_{42}$ immunoassays. The differences in antibody epitope recognition and the part of CSF diluted in buffer during the incubation render methodological differences both qualitatively and quantitatively. aa, amino acids.

\begin{tabular}{|c|c|c|c|c|c|c|}
\hline & Innotest Elisa & Innotest Elisa (4G8) & The genetics & INNO-BIAAlzBio3 & $\begin{array}{l}\text { INNO-BIAA } \beta \\
\text { forms } \\
\end{array}$ & MSD Triplex \\
\hline $\begin{array}{l}\text { Capture } \\
\text { (epitope) }\end{array}$ & $\begin{array}{c}21 \mathrm{~F} 12 \\
(42 \mathrm{C} \text {-terminal })\end{array}$ & $\begin{array}{c}21 \mathrm{~F} 12 \\
(42 \mathrm{C} \text {-terminal })\end{array}$ & $\begin{array}{c}\text { W02 } \\
\text { (aa 5-8) }\end{array}$ & $\begin{array}{c}\text { 4D7A3 } \\
\text { (42 C-terminal) }\end{array}$ & $\begin{array}{c}21 \mathrm{~F} 12 \\
(42 \mathrm{C} \text {-terminal })\end{array}$ & $\begin{array}{c}\text { Not declared } \\
(42 \text { C-terminal) }\end{array}$ \\
\hline $\begin{array}{l}\text { Detection } \\
\text { (epitope) }\end{array}$ & $\begin{array}{c}3 \mathrm{D} 6 \\
(\text { aa } 1-5)\end{array}$ & $\begin{array}{c}4 \mathrm{G} 8 \\
\text { (aa 17-24) }\end{array}$ & $\begin{array}{c}\text { G2-13 } \\
(42 \text { C-terminal) }\end{array}$ & $\begin{array}{c}3 \mathrm{D} 6 \\
(\text { aa } 1-5)\end{array}$ & $\begin{array}{c}3 \mathrm{D} 6 \\
(\text { aa } 1-5)\end{array}$ & $\begin{array}{c}4 \mathrm{G} 8 \\
\text { (aa 17-24) }\end{array}$ \\
\hline $\begin{array}{l}\text { CSF } \\
(\% \mathrm{v} / \mathrm{v})\end{array}$ & 25 & 25 & 50 & 75 & 75 & 50 \\
\hline $\mathrm{A} \beta$ & $1-42$ & $x-42$ & $x-42$ & $1-42$ & $1-42$ & $x-42$ \\
\hline
\end{tabular}

tubes. The tubes were incubated at RT for one hour on a Boule mixer and thereafter stored in a freezer $\left(-80^{\circ} \mathrm{C}\right)$ pending analysis.

Six samples of CSF were divided into three aliquots of which one was run through a lumbar catheter (Braun-Perifix, art. nr. 4513150), one was run through a lumbar pressure meter catheter (Mediplast, art. nr. 6061650008), while the third aliquot was analyzed without any pretreatment.

2.5.2. Incubation, Storage, and Collection of CSF. To test whether $A \beta_{42}$ is sensitive to handling at RT, eight freshly collected samples, within 3 hours after withdrawal, were divided into two aliquots. The first aliquot was analyzed immediately, while the other was analyzed after 24 hours of incubation at RT. Six control samples were set on each plate to adjust the levels according to the interassay variability.

In order to test if $A \beta_{42}$ is sensitive to freezing eight samples of CSF were collected freshly and divided into two aliquots. The first aliquot was analyzed immediately while the second was stored at $-80^{\circ} \mathrm{C}$ for at least one week pending analysis. Two control samples, each analyzed in two duplicates, were used to adjust for interassay variability. The samples were analyzed using Innogenetics ELISA.

Data on the long-term storage stability of $A \beta_{42}$ in CSF at $-80^{\circ} \mathrm{C}$ were retrieved from repeated analyses $(N=214)$ of an internal quality control sample (aliquots of a large CSF pool) during 26 months. The control sample was analyzed in duplicates at each occasion using the Innogenetics ELISA.

To test for the impact of incubation at RT in combination with freezing, twelve samples of CSF were collected freshly and divided into seven aliquots of which one was immediately frozen. The remaining six aliquots were stored at either $+4^{\circ} \mathrm{C}$ or RT for four hours, 24 hours or three days and thereafter frozen pending simultaneous analysis using Innogenetics ELISA.

To test for the sensitivity of different processes of freezing, different freezing temperatures, and different thawing conditions freshly collected CSF from ten subjects was divided into eight aliquots and analyzed. Two aliquots were tested for the process of freezing; one was frozen on dry ice/ethanol and thereafter stored at $-80^{\circ} \mathrm{C}$ for three days while the other was immediately stored at $-80^{\circ} \mathrm{C}$. Three aliquots were frozen at $-20^{\circ} \mathrm{C}$ at stable temperature, $-20^{\circ} \mathrm{C}$ in an auto-defrosting freezer, or $-80^{\circ} \mathrm{C}$ for three days. Three aliquots were stored at $-80^{\circ} \mathrm{C}$ for three days and thereafter tested for thawing in a fridge $\left(+4^{\circ} \mathrm{C}\right)$, at $\mathrm{RT}$ and in a water bath at $+20^{\circ} \mathrm{C}$.

To test whether the initial LP conditions influence the biomarker level, freshly collected CSF from nine subjects was either collected at RT or in tubes placed on ice. The samples were left to incubate for three hours and thereafter frozen at $-80^{\circ} \mathrm{C}$.

2.5.3. A $\beta$ Spinal Chord Gradient. The $\mathrm{A} \beta_{42}$ CSF spinal chord gradient was assessed by sequentially withdrawing four fractions of $10 \mathrm{~mL}$ CSF from seven patients; fraction 1 (0$10 \mathrm{~mL}), 2(11-20 \mathrm{~mL}), 3(21-30 \mathrm{~mL})$ and $4(31-40 \mathrm{~mL})$.

\subsubsection{Contamination of Blood and Blood-Brain Barrier} Dysfunction. To examine if blood contamination influence CSF biomarkers a blood sample was diluted by water and freeze-thawn in dry ice/ethanol in order to lyse erythrocytes. Serially diluted blood equivalent to an erythrocyte level of 200,1000 and $5000 / \mu \mathrm{L}(0.004-0.1 \% \mathrm{v} / \mathrm{v})$ was then added to 10 different CSF samples $(95 \% \mathrm{v} / \mathrm{v})$ and compared with the corresponding water-diluted CSF $(95 \% \mathrm{v} / \mathrm{v})$. The samples were analyzed using Innogenetics ELISA.

To test the influence of blood-brain barrier (BBB) dysfunction on CSF biomarkers a plasma sample was serially diluted by water to an albumin level corresponding of approximately $0.25,0.50,1.0$ and $2.0 \mathrm{~g} / \mathrm{L}(0.625-5 \% \mathrm{v} / \mathrm{v})$ when added to $8 \mathrm{CSF}$ samples $(90 \% \mathrm{v} / \mathrm{v})$ with an albumin level of approximately $0.20 \mathrm{~g} / \mathrm{L}$. The samples were compared with corresponding water-diluted CSF $(90 \% \mathrm{v} / \mathrm{v})$. This series represents different degrees of $\mathrm{BBB}$ permeability with a CSF/serum albumin ratio of $5,11,18,30$ and 55 , respectively (5 equals the CSF baseline level $((0.20 \mathrm{~g} / \mathrm{L} / 40 \mathrm{~g} / \mathrm{L}$ (serum albumin $)) \times 1000)$ ). The samples were analyzed using the Innogenetics ELISA.

2.5.5. The Influence of an Overnight Fast on Plasma $A \beta_{42}$ Levels. Blood was withdrawn at three different occasions from nine cognitively healthy subjects to test whether fasting or subsequent food intake influences the plasma baseline $\mathrm{A} \beta_{42}$ levels. Plasma was preferred as opposed to CSF due to the inconvenience of repeated fluid sampling by LP on healthy subjects. The baseline blood sample was withdrawn 
at nine o'clock in the morning following a nonstandardized breakfast, the follow-up sample after three weeks at the same time in the morning following an overnight fast and the postprandial sample one hour after a standardized breakfast the same day. The samples were analyzed using Innogenetics INNO-BIA plasma $\mathrm{A} \beta$ forms.

2.5.6. Diurnal Variability. CSF from 14 psychiatrically and neurologically healthy subjects undergoing knee prothesis surgery was serially collected by LP with an 18-Gauge Portex epidural needle at baseline, after four to six hours (mean 5.3 hours) and after 24 hours, for further details on this procedure see Anckarsäter et al. [29]. The samples were immediately stored at $-80^{\circ} \mathrm{C}$ pending analysis.

2.5.7. Centrifugation and Heat Denaturation. CSF from ten subjects was divided into three aliquots each of which one was analyzed without any pretreatment. The other two aliquots were centrifuged for ten minutes $(2000 \times \mathrm{g})$, at RT or at $+4^{\circ} \mathrm{C}$ to evaluate the effect of $\mathrm{A} \beta$ precipitation during centrifugation. Furthermore, 18 samples of CSF were divided into two aliquots of which one was boiled at $100^{\circ} \mathrm{C}$ in a heating block for ten minutes. Both samples were thereafter centrifuged at $+4^{\circ} \mathrm{C}$ for ten minutes $(2000 \times \mathrm{g})$.

CSF from $15 \mathrm{AD}$ patients and 15 controls were divided into two aliquots of which one was preincubated for 15 minutes at $100^{\circ} \mathrm{C}$ in a heating block. Both aliquots were centrifuged $(2000 \times \mathrm{g})$ at $+4^{\circ} \mathrm{C}$ for ten minutes and analyzed using the Innogenetics ELISA.

2.5.8. Sample Pretreatment Affecting Assay Analyses. A fresh CSF sample was used to assess the impact of incubation at $\mathrm{RT}$ on changes in $\mathrm{pH}$. The baseline $\mathrm{pH}$ was measured within 30 minutes from LP.

A CSF pool was serially diluted $(50 \%, 25 \%, 6.25 \%$ and $3.125 \% \mathrm{v} / \mathrm{v}$ ) in different buffers as well as in the provided assay buffer. Different buffer concentrations (10, 50 and $100 \mathrm{mM}$ phosphate buffered saline (PBS) ( $\mathrm{pH} \mathrm{7.4)),}$ and different buffer substances (PBS, Tris and HEPES $(\mathrm{pH}$ 7.4)), were tested for the effect on the measured $\mathrm{A} \beta_{42}$ concentration. Furthermore, the effect on assay performance at different $\mathrm{pH}$ was evaluated in $50 \mathrm{mM}$ Tris $(\mathrm{pH} 7.4,8$, and 9). The addition of $0.1 \% \mathrm{v} / \mathrm{v}$ Tween $20,0.05 \% \mathrm{v} / \mathrm{v}$ Triton $\mathrm{X} 100$ and $0.5 \mathrm{mg} / \mathrm{mL}$ BSA to $50 \mathrm{mM}$ PBS (pH7.4) was used to further assess the improvement of $\mathrm{A} \beta_{42}$ detection.

\subsubsection{Epitope Masking and/or Assay Specific Variability.} Divergences in measured $\mathrm{A} \beta$ concentration levels between different commercially available $\mathrm{A} \beta_{42}$ assays were evaluated and the assays were compared with respect to how well they perform in discriminating between $\mathrm{AD}$ patients and healthy controls. CSF from patients with $\mathrm{AD}(n=20)$ and healthy controls $(n=20)$ was analyzed using assays from Innogenetics (ELISA, Abeta forms, and AlzBio3), MesoScale Discovery (Triplex), and The Genetics (ELISA). The commercial Innogenetics ELISA was also tested by replacing the detection antibody with the monoclonal antibody $4 \mathrm{G} 8$. Neat and threefold diluted (0.05\% Tween 20 in PBS) CSF samples were analyzed according to the instructions from the manufacturers.

\section{Results and Discussion}

3.1. Adsorption to Test Tubes and Lumbar Catheter Walls. The $\mathrm{A} \beta_{42}$ levels were significantly altered by storage in different test tubes. The $\mathrm{A} \beta_{42}$ levels significantly decreased when CSF was stored in polystyrene tubes $(208 \mathrm{ng} / \mathrm{L}(126-$ 467)) compared with polypropylene (271 ng/L (152-478)), as previously shown by others $[23,30,31]$, rendering a significantly decreased $\mathrm{A} \beta_{42}$ level of as much as $35 \%$ (mean decrease $19 \% ; P=.002$ ). The A $\beta_{42}$ level also decreased when CSF was stored in glass tubes compared with polypropylene, however it did not reach statistical significance. Some of the previously reported differences in absolute values of $\mathrm{A} \beta_{42}$ might thus be due to adsorption to different test tubes probably caused by the hydrophobic nature of this analyte. In consequence, standardization of collection tubes is necessary in order to be able to compare absolute concentration values among different centers.

Adhesion of $\mathrm{A} \beta_{42}$ to the lumbar catheter walls during LP might also render a difference in analyte concentration and would urge for standardization. However, two different catheters were tested of which none significantly altered the concentration of $\mathrm{A} \beta_{42}$ as compared with the baseline level.

3.2. Incubation, Storage and Collection of CSF. It is essential for reliable biochemical analysis that the stability of a biomarker is thoroughly investigated in order to implement the appropriate preanalytical handling. Eight CSF samples were analyzed within three hours from withdrawal and after 24 hours of incubation at RT. No significant difference between the paired samples was detected in the $A \beta_{42}$ levels suggesting that this biomarker is stable when left for at least a day at RT. Furthermore, no significant alteration in the level of $\mathrm{A} \beta_{42}$, as previously described [32], was found between fresh CSF and CSF that had undergone one freeze/thaw cycle. Nor were there any significant differences between the baseline $\mathrm{A} \beta_{42}$ levels of freshly frozen samples and samples frozen after incubation at RT or at $+4^{\circ} \mathrm{C}$ for four hours, 24 hours or three days. These results are in contrast to one study, which found $\mathrm{A} \beta_{42}$ to be decrease by $20 \%$ after two days incubation at RT, while no difference was found when comparing fresh CSF to frozen/thawed CSF [33]. However, the fresh CSF had been incubated at RT during two days, which would mean that the level of $A \beta_{42}$ implemented as a baseline value was decreased and thus also the $\mathrm{A} \beta_{42}$ level in the frozen CSF. Furthermore, the study had a very limited sample size which may contribute to the divergent results. Another study showed, contradictory to ours, that the $\mathrm{A} \beta_{42}$ concentration was increased after 24 hours of incubation at RT [34]. However, the CSF was not centrifuged prior to incubation which seems to affect the outcome, see below.

The storage stability of CSF $\mathrm{A} \beta_{42}$ at $-80^{\circ} \mathrm{C}$ was assessed through an internal quality control sample which was analyzed on a weekly basis during a time period of 26 months. The coefficient of variation $(\mathrm{CV})$ on 214 different 




FIgure 1: The mean $A \beta_{42}$ variation in CSF during 26 months. An internal quality control sample was run on 214 different occasions rendering a mean $\pm \mathrm{SD}$ value $(-)$ of $643 \pm 48 \mathrm{ng} / \mathrm{L}$ and a $\mathrm{CV}$ of $7.5 \%$.

runs was $7.5 \%$, which is less than the inter assay $\mathrm{CV}$ (7.7\%) reported by the manufacturer (Innogenetics NV) and consequently signify the storage stability of $\mathrm{A} \beta_{42}$ during the accounted time period (Figure 1). The storage stability of $\mathrm{A} \beta_{42}$ in CSF during shorter time periods has previously been reported further supporting this finding [35].

No significant changes accounting for larger differences than the intraindividual assay CV (3.8\%) was seen for neither of the various routes for freezing, the different storage temperatures, nor the diverse thawing procedures. Moreover, no difference in $A \beta_{42}$ concentration was found when comparing CSF collected and incubated in tubes placed on ice during the LP procedure compared with CSF collected and incubated at RT. This is an indication of the $\mathrm{A} \beta_{42}$ stability and supports the use of this peptide as a CSF biomarker. However, other proteins may be sensitive to storage at $-20^{\circ} \mathrm{C}$. Storage at $-20^{\circ} \mathrm{C}$ causes, for instance, a truncation in Cystatin $\mathrm{C}$ revealed by a peptide artifact identified by gel electrophoresis and mass spectrometry [36, 37]. Therefore, it is recommendable to store CSF samples at $-80^{\circ} \mathrm{C}$ as a precaution to possible future analyses.

3.3. A $\beta$ Spinal Chord Gradient. Since CSF proteins originating from brain cells may have a decreasing rostro-caudal concentration gradient, while proteins released from the leptomeninges and blood derived proteins have a lower ventricular than lumbar CSF concentration, withdrawal of different CSF volumes might affect the outcome of biochemical analysis [38]. By withdrawing a small volume of CSF the biochemical composition might only reflect that of the lumbar dural sac and the withdrawal of a too large volume might influence the analysis as to increase the concentration of a brain specific protein. No spinal chord gradient was detected for $\mathrm{A} \beta_{42}$ when successively withdrawing four $10 \mathrm{~mL}$ portions CSF; that is, the four portions did not significantly differ in their $\mathrm{A} \beta_{42}$ level. Although there was no gradient for CSF $A \beta_{42}$ along the spinal chord, it is still recommended to take a standardized volume of CSF at LP since other proteins such as albumin [39] and especially neurotransmitters [40] will be affected.

3.4. Contamination of Blood and Blood-Brain Barrier Dysfunction. It is not uncommon that the CSF gets contaminated by blood during the LP procedure [41]. Since the concentration of proteins in CSF is about $0.5 \%$ that of blood [42] only a minor leakage could lead to an altered biomarker profile. Furthermore, blood contamination of CSF could lead to an increase in protein degradation already visible after 6 hours of incubation [43]. Therefore, it is important that contaminated CSF is discarded and that CSF is centrifuged as soon as possible after LP to get rid of contaminants invisible to the eye. Consequently, the addition of $0.1 \%$, $0.02 \%$ and $0.004 \%$ (corresponding to 5000, 1000 and 200 erythrocytes $/ \mu \mathrm{L}$ ) of blood to CSF should provide reliable information on the impact of contamination, unnoticeable to the eye, on the $\mathrm{A} \beta_{42}$ levels. However, no significant changes accounting for larger differences than the intraindividual assay CV was seen when comparing CSF contaminated with blood to neat CSF (Figure 2(a)).

Neat CSF was compared with CSF with added plasma, corresponding to a CSF/serum albumin ratio of 5,11 , 18,30 and 55, (i.e., a range from normal to pathological blood-CSF barrier function), and the $\mathrm{A} \beta_{42}$ concentration in the diluted CSF was significantly $(P=.008)$ decreased by as much as $49 \%(228 \mathrm{ng} / \mathrm{L}(165-378))$ compared with the neat CSF $\mathrm{A} \beta_{42}$ concentration (433 ng/L (291-851)) (Figure 2(b)). One explanation to the decrease might be a high concentration of several proteins that bind $A \beta$ in plasma, such as albumin [44], $\alpha 2$-macroglobulin [45] and low-density receptor related protein-1 [46], and it might explain the fact that numerous studies have found no correlation between CSF and plasma levels of $\mathrm{A} \beta$ biomarkers $[32,47]$, for review see [48]. It may be important to consider the albumin ratio when evaluating the concentration of $A \beta_{42}$ in CSF in disorders with severe impairment of the BBB, such as acute meningitis [49], due to the impact of plasma on the measured CSF A $\beta$ levels.

3.5. The Influence of an Overnight Fast on Plasma A $\beta_{42}$ Levels. Even though the absolute CSF $\mathrm{A} \beta_{42}$ values have diverged among different centers the decreased $A \beta_{42}$ levels in $A D$ compared with controls have been consistent. The possible influence of an overnight fast or food intake on $\mathrm{A} \beta_{42}$ levels has been brought forward mainly due to inconsistencies in studies concerning the plasma levels of $\mathrm{A} \beta$ [48]. However, in this study there was no significant difference between the baseline plasma $A \beta_{42}$ level compared with either fasting or postprandial levels. Furthermore, it would thus seem unlikely that the CSF A $\beta$ levels would be affected when the plasma levels were not.

3.6. Diurnal Variability. Diurnal variability in CSF A $\beta$ levels would give cause for a standardized sampling time for everyday clinical routine. In a previous study, wherein $6 \mathrm{~mL}$ of CSF was withdrawn each hour, it was shown that $A \beta$ had a large diurnal variability [50]. During a time period of 


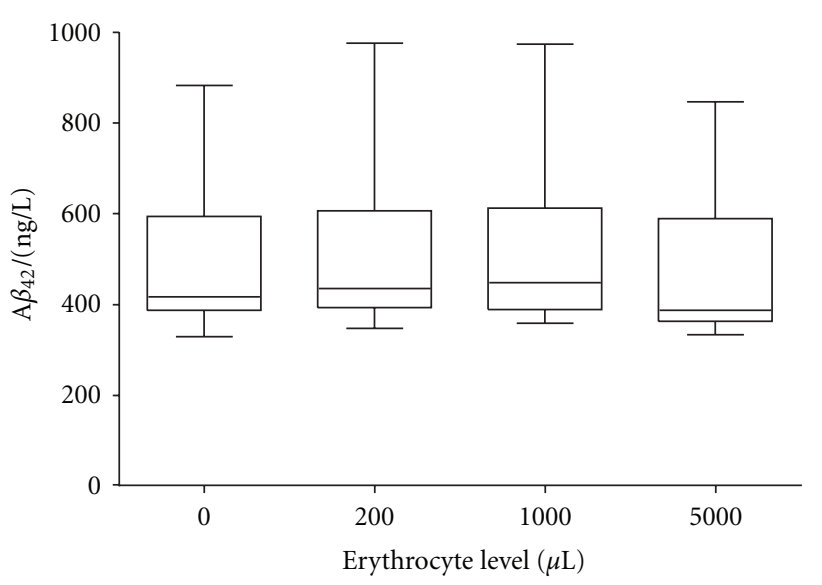

(a)



(b)

FIGURE 2: Boxplots with whiskers representing minutes and max values. (a) The effect of blood contamination on CSF A $\beta_{42}$ levels. The addition of blood to CSF representing an erythrocyte level of 200,1000 and $5000 / \mu \mathrm{L}$ of blood did not affect the $\mathrm{A} \beta_{42}$ level compared with neat CSF. (b) The effect a blood-brain barrier dysfunction on $\mathrm{A} \beta_{42}$ levels. Plasma was added to CSF at a concentration representing a $\mathrm{CSF} /$ serum albumin ratio of 11 , 18,30 and 55 . The $\mathrm{A} \beta_{42}$ concentration was significantly decreased $(P<.01)$ at all added plasma concentrations.

36 hours, the $\mathrm{A} \beta$ levels peaked at 12 hours and 23 hours with troughs at baseline and 25 hours with significant fluctuations of more than $50 \%$ within 6 hours. However, no complete return to baseline values was seen for $\mathrm{A} \beta$. Our data showed more stable levels with a slight but significant decrease of 9.3\% $(P<.001)$ in CSF A $\beta_{42}$ after $4-6$ hours (mean 5.3 hours), which tended to return to baseline levels after 24 hours (4.4\% lower than baseline; $P=.002$ ).

In this study, our attempt was to reflect the variation in CSF withdrawal time that might be a reality in some clinical settings. One explanation to the difference between our results and the study by Bateman et al. [50] might be that a smaller CSF volume was taken, which may cause less effect on the CSF dynamics. Even though the CSF A $\beta_{42}$ level does not seem to be influenced by circadian rhythms

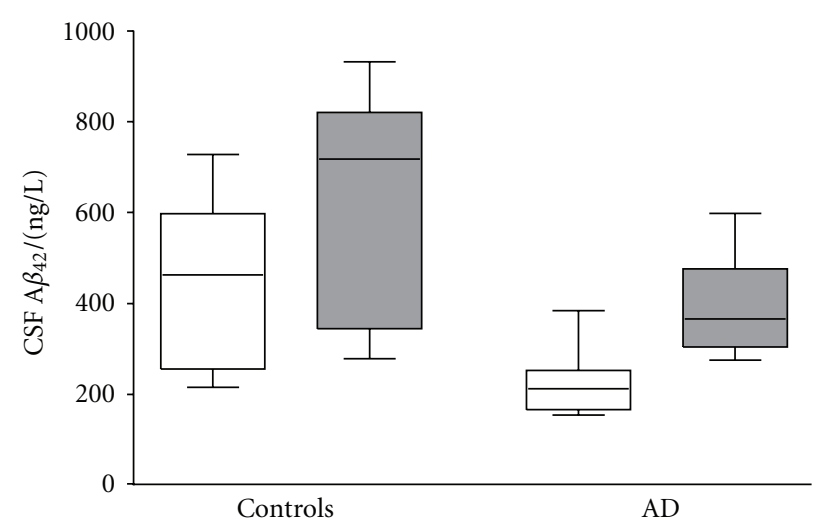

Figure 3: Boxplot (whiskers represent minutes and max values) of measured concentrations of $\mathrm{A} \beta_{42}$ in untreated and heat denatured CSF. The white boxes represent untreated CSF and dark boxes represent heat denatured CSF. Each box represents 15 samples (15 $\mathrm{AD}$ or 15 controls).

to any greater extent, other analytes might be which would support a standardized time interval during the day for CSF withdrawal.

3.7. Centrifugation and Heat Denaturation. Ten samples were divided into three aliquots in order to test for precipitation during centrifugation, with and without cooling during the process. There was a significant $(P=.002)$ decrease in the concentration of $A \beta_{42}$ in both of the centrifuged samples (RT $203 \mathrm{ng} / \mathrm{L}(138-340) ;+4^{\circ} \mathrm{C} 203 \mathrm{ng} / \mathrm{L}(139-341)$ ) when compared with the noncentrifuged samples (228 ng/L (147354)). This indicates that a portion of $\mathrm{A} \beta_{42}$ in CSF might originate from cells that have undergone lysis that would precipitate together with the cells during the process of centrifugation. Furthermore, the $\mathrm{A} \beta$ fraction accessible to the antibody was further addressed by exposing CSF to heat denaturation. Herein, $18 \mathrm{CSF}$ samples were divided into one heat exposed aliquot versus one unexposed aliquot and both were submitted to centrifugation prior to analysis. The $\mathrm{A} \beta_{42}$ concentration increased significantly $(P<.001)$ in the heat treated samples $(278 \mathrm{ng} / \mathrm{L}(170-471))$ as compared with the untreated samples (210 ng/L (127-357)). This result was replicated in a case control study were the increase of $\mathrm{A} \beta_{42}$ was larger in the $\mathrm{AD}$ patient group $(71 \%, P<$ $.001)$ compared with the control group $(42 \%, P<.001)$ (Figure 3). Consequently, the ROC analysis revealed a decreased discriminating power between $\mathrm{AD}$ and controls after heat treatment (AUC $=0.796$ ) compared with the untreated samples (AUC $=0.907$ ). The correlation for both test samples was high $\left(r_{s}>0.8, P<.001\right)$, when comparing untreated versus treated samples, indicating methodological stability.

3.8. Sample Pretreatment Affecting Assay Analysis. Factors known to affect the solubility and stability of proteins were investigated for its cofounding effects during analysis. Different buffer concentrations (10,50 and $100 \mathrm{mM}$ PBS, $\mathrm{pH}$ 7.4) and different buffer substances (PBS, Tris and 
HEPES, pH 7.4) did not affect the CSF $A \beta_{42}$ measurement performance compared with the provided assay buffer. The $\mathrm{pH}$ of CSF was investigated and found to increase rapidly in RT from a starting value of $\mathrm{pH} 7.9$ and reaching a plateau at $\mathrm{pH} 8.7$ already after five hours. To test if the $\mathrm{A} \beta_{42}$ antibody binding capacity is altered due to differences in $\mathrm{pH}$ during analysis, which could be a confounding factor if employing a buffer with a low buffer capacity, pooled CSF was tested in three different $\mathrm{pH}$ systems $(50 \mathrm{mM}$ Tris, $\mathrm{pH} 7.4,8$ and 9). Compared with the levels of $\mathrm{A} \beta_{42}$ obtained in provided assay buffer system, the different $\mathrm{pH}$ tested did not alter the $\mathrm{A} \beta_{42}$ levels. Furthermore, BSA $(0.5 \mathrm{mg} / \mathrm{mL})$ and two different detergents $(0.05 \%$ Triton 100 and $0.1 \%$ Tween 20$)$ were added to test if the signal of $A \beta_{42}$ could be improved by possibly decreasing the negative effects of protein interaction with the solid surface of the beads and/or the air-liquid interface. The signal was equally improved for all three additives (data not shown) as compared with the assay buffer system and the detergent effect was further assessed, what follows.

3.9. Epitope Masking and/or Assay Specific Variability. One hypothesis for the decreased level of $\mathrm{A} \beta_{42}$ in CSF from $\mathrm{AD}$ patients is that plaques in the brain act as sinks for $\mathrm{A} \beta_{42}$, preventing it from reaching the CSF. In CSF $A \beta$ may either exist as a free soluble peptide, as oligomers [51], or bound in complex with carrier proteins such as $\alpha$-2-macroglobulin [52], apolipoprotein E (ApoE) [53], apolipoprotein J (ApoJ; Clusterin) [54, 55], albumin [44], low-density lipoprotein receptor-related protein-1 (LRP) [56], and transthyretin [57]. The APOE $\varepsilon 4$ allele is the strongest known genetic risk factor for $\mathrm{AD}[58,59]$. Carrier proteins such as ApoE are thought to play a part in the $\mathrm{A} \beta$ clearance and an altered clearance effect, in this case, is thought to be allele specific due to a decreased binding efficiency between $\mathrm{A} \beta$ and $\mathrm{ApoE} 4$ as compared with the other isoforms [60].

CSF samples were treated with either detergent or heat denaturation, which has previously been shown to increase the $\mathrm{A} \beta_{42}$ measureable level $[61,62]$, to assess the fraction of possibly bound/epitope masked $A \beta_{42}$ in proportion to the free $A \beta_{42}$ in untreated samples and whether the total amount of $A \beta_{42}$ could further improve the differentiation between $\mathrm{AD}$ and controls. The measured concentration of $\mathrm{A} \beta_{42}$ increased after the threefold dilution with the detergent containing buffer. The most striking increases were found for the xMAP assays AlzBio3 and $\mathrm{A} \beta$ forms. The $\mathrm{A} \beta_{42}$ median concentration for the neat CSF samples varied by more than a factor of eight, between the different assays tested (Figure 4(a)). The variation in the median is still present in the diluted samples but markedly reduced to less than a factor of three. To further investigate the result, the correlations between the assays were calculated (Table 2). Almost all tests, both neat and diluted, resulted in a difference in $\mathrm{A} \beta_{42}$ concentrations between $\mathrm{AD}$ and controls with $P<$ .005 . Only the ELISA assay from The Genetics failed to reach significance at this level with $P=.086$ and $P=.017$ for neat and diluted CSF, respectively.

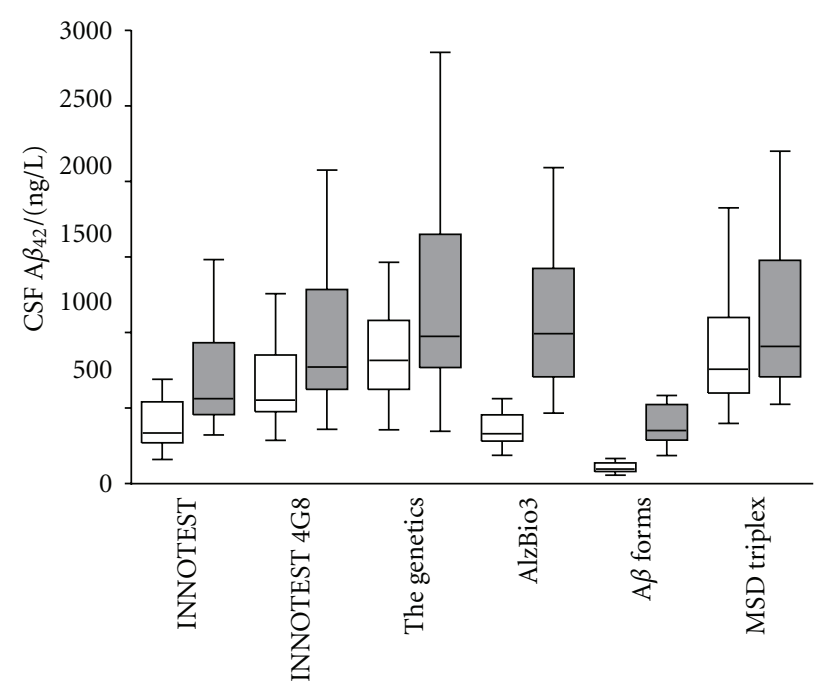

(a)

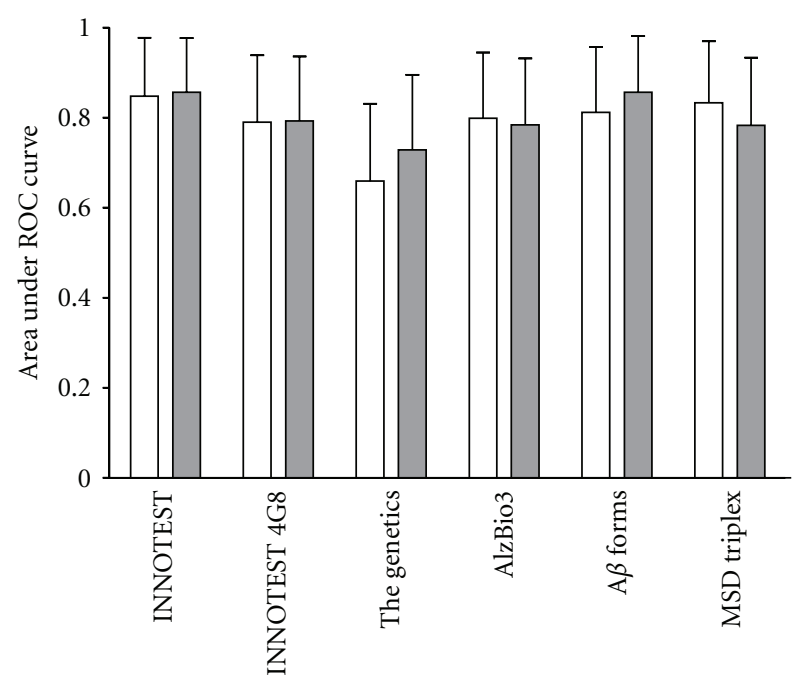

(b)

Figure 4: (a) Boxplot (whiskers represent minutes and max values) of CSF $\mathrm{A} \beta_{42}$ concentrations using different assays. For each kit the CSF was analyzed twice, neat and threefold diluted in a detergent-containing buffer. Each box represents 40 samples (20 $\mathrm{AD}+20$ controls). (b) Area under ROC curve for different assays with whiskers representing a 95\% confidence interval. Neat, and threefold diluted CSF are represented by white and dark boxes/bars, respectively.

The area under the ROC curve was used as a measure of the discrimination power for the assays (Figure 4(b)). Most of the assays performed equally well in discriminating between $\mathrm{AD}$ patients and healthy controls and there were no specific trend in the performance when the CSF was threefold diluted. Even though there are large differences in $\mathrm{A} \beta_{42}$ concentration depending on which assay is used most of the correlations between the assays are strong which indicates that the differences in measured concentrations are not due to cross reactivity for other substances than 
TABle 2: Correlation matrix for the evaluated $\mathrm{A} \beta$ assays. The correlation between the levels of $\mathrm{A} \beta_{42}$ in different assays. The correlation coefficients for the neat and diluted CSF samples are shown in the upper right and lower left part, respectively.

\begin{tabular}{lccccc}
\hline & $\begin{array}{c}\text { Innogenetics } \\
\text { ELISA (4G8) }\end{array}$ & $\begin{array}{c}\text { Innogenetics } \\
\text { ELISA }\end{array}$ & $\begin{array}{c}\text { The Genetics } \\
\text { ELISA }\end{array}$ & $\begin{array}{c}\text { Innogenetics } \\
\text { AlzBio3 }\end{array}$ & $\begin{array}{c}\text { Innogenetics } \\
\text { A } \beta \text { forms }\end{array}$ \\
\hline Innogenetics ELISA (4G8) & 1 & 0.94 & 0.90 & 0.87 & 0.69 \\
Tnnogenetics ELISA & 0.96 & 1 & 0.82 & 0.93 & 0.97 \\
The Genetics ELISA & 0.93 & 0.88 & 1 & 0.75 & 0.81 \\
Innogenetics AlzBio3 & 0.92 & 0.94 & 0.89 & 1 & 0.53 \\
Innogenetics A $\beta$ forms & 0.78 & 0.86 & 0.67 & 0.86 & 0.88 \\
MSD Triplex & 0.98 & 0.96 & 0.93 & 0.93 & 0.84 \\
\hline
\end{tabular}

$\mathrm{A} \beta_{42}$. One possible explanation for the variation is that kit manufacturers have different sources for the $\mathrm{A} \beta_{42}$ standard that is used for calibration. This result highlights the need for an external $\mathrm{A} \beta_{42}$ control program that would allow manufacturers to calibrate their assays towards a common standard. The reason for the increase in measured concentration of $\mathrm{A} \beta_{42}$ upon dilution is at present unknown but might involve dissociation of $\mathrm{A} \beta$ homo- or heterocomplexes which would liberate more $\mathrm{A} \beta_{42}$ that are otherwise masked for detection. If this is true the results from the diluted samples would more truly reflect the total $\mathrm{A} \beta_{42}$ concentration, which potentially could be an even better biomarker than the "free" $\mathrm{A} \beta_{42}$ measured in the undiluted samples. However, there were no dramatic changes in the discriminating power in the diluted CSF compared with neat samples. Besides, methodological reasons for the increase cannot be excluded since the most dramatic changes are for the two assays based on the xMAP technology (Innogenetics' AlzBio3 and $\mathrm{A} \beta$ forms). Herein, it is clearly shown that divergences in absolute $A \beta_{42}$ levels between different centers could be explained by the fact that different ELISAs are utilized with different protocols as well as assay methodologies (Table 1). However, when different centers employ the same ELISA from the same manufacturer divergences often still remain [63]. Another factor affecting the $A \beta$ concentration inconsistency might be the result of a lot-to-lot variability [64].

Detergent and heat treatments give rise to a similar increase in the measured level of $\mathrm{A} \beta_{42}$ in the $\mathrm{AD}$ groups, $75 \%$ and $71 \%$, respectively. In contrast, the detergent treated control CSF diverged from the heat denatured by a more pronounced increase ( $83 \%$ versus $42 \%$ ). Whether the divergences in the increase of $\mathrm{A} \beta_{42}$ levels between the two differently treated CSF samples of the controls and the discriminating power between neat/detergent CSF compared with native/denatured samples could be explained by the differences in study sample, methodological reasons or differences in complex stability needs to be addressed by further studies.

\section{Conclusion}

Due to the high between-center variability (possibly caused by preanalytical and analytical factors) of reported $\mathrm{A} \beta_{42}$ levels in CSF, possible confounding factors were assessed in relation to the CSF $\mathrm{A} \beta_{42}$ levels. The confounding factors found to influence the preanalytical procedures for CSF collection and sample processing, analytical procedures and techniques ultimately leading to altered $\mathrm{A} \beta_{42}$ concentrations are summarized below.

Preanalytical Factors. (i) Increased $\mathrm{A} \beta_{42}$ concentration in noncentrifuged CSF samples possibly due to a release of the analyte caused by cell lysis - it is important to centrifuged CSF within a standardized time interval after LP.

(ii) Decreased $\mathrm{A} \beta_{42}$ levels due to adsorption of analyte to different types of test tubes-standardization of test tubes used for CSF sampling that is, polypropylene.

(iii) Pretreatment of CSF with detergent-containing buffers or heat denaturation lead to an increase in $\mathrm{A} \beta_{42}$ levels - probably due to dissociation of $\mathrm{A} \beta$ bound to proteins or release of $\mathrm{A} \beta$ from oligomers. For these reasons a standardization of dilution factors, buffer additives and sample processing is necessary prior to analysis.

(iv) The CSF $\mathrm{A} \beta_{42}$ concentration decreased at the addition of plasma corresponding to a CSF/serum albumin ratio of 11-55-probably due to the binding of free $\mathrm{A} \beta$ to plasma proteins.

Analytical Factors. (i) Different immuno-assays employing various antibodies and possibly dissimilar sources for the calibrator peptides lead to divergences in the absolute $\mathrm{A} \beta_{42}$ concentration-between center comparisons cannot be made when employing different assays. This problem cannot be solved until an international $\mathrm{A} \beta$ golden standard is available.

Even though the CSF concentration of $\mathrm{A} \beta_{42}$ does not seem to be affected by a spinal chord gradient, circadian rhythms, blood contamination or by storage/thawing conditions other proteins may be. It is necessary to use a standardized protocol to allow for between-center comparisons, for a detailed protocol see Blennow et al. [9].

\section{Disclosure}

K. Blennow has participated in an advisory board for the Innogenetics. The other authors have nothing to disclose. 


\section{Acknowledgments}

This work was supported by Grants from the Swedish Brain Power, Swedish Research Council (Projects 14002, 20066227, 2006-2740, and 2006-3505), the Alzheimer's Association (NIRG-08-90356), cNEUPRO, the Royal Swedish Academy of Sciences, the Sahlgrenska University Hospital, the Inga-Britt and Arne Lundberg Research Foundation, the Göteborg Medical Society, the Swedish Medical Society, Demensfonden, Stiftelsen Gamla Tjänarinnor, Gun och Bertil Stohnes stiftelse, Alzheimer Foundation, Sweden. The authors are grateful to Monica Christiansson, Åsa Källén, and Sara Hullberg for their technical support.

\section{References}

[1] A. Wimo, B. Winblad, H. Aguero-Torres, and E. von Strauss, "The magnitude of dementia occurrence in the world," Alzheimer Disease and Associated Disorders, vol. 17, no. 2, pp. 63-67, 2003.

[2] A. Lobo, L. J. Launer, L. Fratiglioni et al., "Prevalence of dementia and major subtypes in Europe: a collaborative study of population-based cohorts. Neurologic Diseases in the Elderly Research Group," Neurology, vol. 54, no. 11, supplement 5, pp. S4-S9, 2000.

[3] H. Braak and E. Braak, "Neuropathological stageing of Alzheimer-related changes," Acta Neuropathologica, vol. 82, no. 4, pp. 239-259, 1991.

[4] B. E. Tomlinson, G. Blessed, and M. Roth, "Observations on the brains of demented old people," Journal of the Neurological Sciences, vol. 11, no. 3, pp. 205-242, 1970.

[5] K. Blennow, M. J. de Leon, and H. Zetterberg, "Alzheimer's disease," The Lancet, vol. 368, no. 9533, pp. 387-403, 2006.

[6] K. Blennow and H. Zetterberg, "Cerebrospinal fluid biomarkers for Alzheimer's disease," Journal of Alzheimer's Disease, vol. 18, no. 2, pp. 413-417, 2009.

[7] P. Davies, J. Resnick, B. Resnick et al., "Consensus report of the working group on: "Molecular and biochemical markers of Alzheimer's disease"," Neurobiology of Aging, vol. 19, no. 2, pp. 109-116, 1998.

[8] J. Hardy and D. J. Selkoe, "The amyloid hypothesis of Alzheimer's disease: progress and problems on the road to therapeutics," Science, vol. 297, no. 5580, pp. 353-356, 2002.

[9] K. Blennow, H. Hampel, M. Weiner, and H. Zetterberg, "Cerebrospinal fluid and plasma biomarkers in Alzheimer disease," Nature Reviews Neurology, vol. 6, no. 3, pp. 131-144, 2010.

[10] N. Mattsson, H. Zetterberg, O. Hansson et al., "CSF biomarkers and incipient Alzheimer disease in patients with mild cognitive impairment," Journal of the American Medical Association, vol. 302, no. 4, pp. 385-393, 2009.

[11] J. C. Morris and J. L. Price, "Pathologic correlates of nondemented aging, mild cognitive impairment, and early-stage Alzheimer's disease," Journal of Molecular Neuroscience, vol. 17, no. 2, pp. 101-118, 2001.

[12] K. Blennow, "Cerebrospinal fluid protein biomarkers for Alzheimer's disease," NeuroRx, vol. 1, no. 2, pp. 213-225, 2004.

[13] K. Blennow and H. Hampel, "CSF markers for incipient Alzheimer's disease," Lancet Neurology, vol. 2, no. 10, pp. 605$613,2003$.
[14] S.-K. Herukka, M. Hallikainen, H. Soininen, and T. Pirttilä, "CSF A $\beta 42$ and tau or phosphorylated tau and prediction of progressive mild cognitive impairment," Neurology, vol. 64, no. 7, pp. 1294-1297, 2005.

[15] O. Hansson, H. Zetterberg, P. Buchhave, E. Londos, K. Blennow, and L. Minthon, "Association between CSF biomarkers and incipient Alzheimer's disease in patients with mild cognitive impairment: a follow-up study," Lancet Neurology, vol. 5, no. 3, pp. 228-234, 2006.

[16] I. Skoog, P. Davidsson, Ó. Aevarsson, H. Vanderstichele, E. Vanmechelen, and K. Blennow, "Cerebrospinal fluid betaamyloid 42 is reduced before the onset of sporadic dementia: a population-based study in 85-year-olds," Dementia and Geriatric Cognitive Disorders, vol. 15, no. 3, pp. 169-176, 2003.

[17] D. R. Gustafson, I. Skoog, L. Rosengren, H. Zetterberg, and K. Blennow, "Cerebrospinal fluid $\beta$-amyloid 1-42 concentration may predict cognitive decline in older women," Journal of Neurology, Neurosurgery and Psychiatry, vol. 78, no. 5, pp. 461464, 2007.

[18] T. Sunderland, G. Linker, N. Mirza et al., "Decreased $\beta$ amyloid1-42 and increased tau levels in cerebrospinal fluid of patients with Alzheimer disease," Journal of the American Medical Association, vol. 289, no. 16, pp. 2094-2103, 2003.

[19] M. Plebani, "Errors in clinical laboratories or errors in laboratory medicine?" Clinical Chemistry and Laboratory Medicine, vol. 44, no. 6, pp. 750-759, 2006.

[20] American Psychiatric Association, Diagnostic and Statistical Manual of Mental Disorders, American Psychiatric Association, Washington DC, USA, 3rd edition, 1987.

[21] G. McKhann, D. Drachman, and M. Folstein, "Clinical diagnosis of Alzheimer's disease: report of the NINCDS-ADRDA work group under the auspices of Department of Health and Human Services Task Force on Alzheimer's disease," Neurology, vol. 34, no. 7, pp. 939-944, 1984.

[22] A. Olsson, H. Vanderstichele, N. Andreasen et al., "Simultaneous measurement of $\beta$-amyloid(1-42), total tau, and phosphorylated tau (Thr181) in cerebrospinal fluid by the xMAP technology," Clinical Chemistry, vol. 51, no. 2, pp. 336345, 2005.

[23] H. Vanderstichele, K. Blennow, N. D'Heuvaert, et al., "Development of a specific diagnostic test for measurement of $\beta$-amyloid(1-42) in CSF," in Progress in Alzheimer's and Parkinson's Diseases, A. Fisher, I. Hanin, and M. Yoshida, Eds., pp. 773-778, Plenum Press, New York, NY, USA, 1998.

[24] H. Vanderstichele, E. Van Kerschaver, C. Hesse et al., "Standardization of measurement of $\beta$-amyloid $((1-42))$ in cerebrospinal fluid and plasma," Amyloid, vol. 7, no. 4, pp. 245-258, 2000.

[25] K. Blennow, G. de Meyer, O. Hansson et al., "Evolution of $\mathrm{A} \beta 42$ and $\mathrm{A} \beta 40$ levels and $\mathrm{A} \beta 42 / \mathrm{A} \beta 40$ ratio in plasma during progression of Alzheimer's disease: a multicenter assessment," Journal of Nutrition, Health and Aging, vol. 13, no. 3, pp. 205208, 2009.

[26] S. F. Hansson, U. Andréasson, M. Wall et al., "Reduced levels of amyloid- $\beta$-binding proteins in cerebrospinal fluid from Alzheimer's disease patients," Journal of Alzheimer's Disease, vol. 16, no. 2, pp. 389-397, 2009.

[27] N. Ida, T. Hartmann, J. Pantel et al., "Analysis of heterogeneous $\beta$ A4 peptides in human cerebrospinal fluid and blood by a newly developed sensitive western blot assay," Journal of Biological Chemistry, vol. 271, no. 37, pp. 22908-22914, 1996. 
[28] M. Jensen, T. Hartmann, B. Engvall et al., "Quantification of Alzheimer amyloid beta peptides ending at residues 40 and 42 by novel ELISA systems," Molecular Medicine, vol. 6, no. 4, pp. 291-302, 2000.

[29] R. Anckarsäter, N. Vasic, L. Jidéus et al., "Cerebrospinal fluid protein reactions during non-neurological surgery," Acta Neurologica Scandinavica, vol. 115, no. 4, pp. 254-259, 2007.

[30] P. Lewczuk, G. Beck, H. Esselmann et al., "Effect of sample collection tubes on cerebrospinal fluid concentrations of tau proteins and amyloid $\beta$ peptides," Clinical Chemistry, vol. 52, no. 2, pp. 332-334, 2006.

[31] N. Andreasen, C. Hesse, P. Davidsson et al., "Cerebrospinal fluid $\beta$-amyloid $((1-42))$ in Alzheimer disease: differences between early- and late-onset Alzheimer disease and stability during the course of disease," Archives of Neurology, vol. 56, no. 6, pp. 673-680, 1999.

[32] M. Sjögren, H. Vanderstichele, H. Ågren et al., “Tau and A $\beta 42$ in cerebrospinal fluid from healthy adults 21-93 years of age: establishment of reference values," Clinical Chemistry, vol. 47, no. 10, pp. 1776-1781, 2001.

[33] N. S. M. Schoonenboom, C. Mulder, H. Vanderstichele et al., "Effects of processing and storage conditions on amyloid $\beta$ (142) and tau concentrations in cerebrospinal fluid: implications for use in clinical practice," Clinical Chemistry, vol. 51, no. 1, pp. 189-195, 2005.

[34] E. Kaiser, P. Schönknecht, P. A. Thomann, A. Hunt, and J. Schröder, "Influence of delayed CSF storage on concentrations of phospho-tau protein (181), total tau protein and betaamyloid (1-42)," Neuroscience Letters, vol. 417, no. 2, pp. 193 195, 2007.

[35] N. Andreasen, L. Minthon, P. Davidsson et al., "Evaluation of CSF-tau and CSF-A $\beta 42$ as diagnostic markers for Alzheimer disease in clinical practice," Archives of Neurology, vol. 58, no. 3, pp. 373-379, 2001.

[36] O. Carrette, P. R. Burkhard, S. Hughes, D. F. Hochstrasser, and J.-C. Sanchez, "Truncated cystatin C in cerebrospiral fluid: technical artefact or biological process?" Proteomics, vol. 5, no. 12, pp. 3060-3065, 2005.

[37] S. F. Hansson, A. H. Simonsen, H. Zetterberg et al., "Cystatin $\mathrm{C}$ in cerebrospinal fluid and multiple sclerosis," Annals of Neurology, vol. 62, no. 2, pp. 193-196, 2007.

[38] H. Reiber, "Proteins in cerebrospinal fluid and blood: barriers, CSF flow rate and source-related dynamics," Restorative Neurology and Neuroscience, vol. 21, no. 3-4, pp. 79-96, 2003.

[39] K. Blennow, P. Fredman, A. Wallin, C.-G. Gottfries, G. Langstrom, and L. Svennerholm, "Protein analyses in cerebrospinal fluid: I. Influence of concentration gradients for proteins on cerebrospinal fluid/serum albumin ratio," European Neurology, vol. 33, no. 2, pp. 126-128, 1993.

[40] K. Blennow, A. Wallin, C. G. Gottfries, J.-E. Mansson, and L. Svennerholm, "Concentration gradients for monoamine metabolites in lumbar cerebrospinal fluid," Journal of Neural Transmission-Parkinson's Disease and Dementia Section, vol. 5, no. 1, pp. 5-15, 1993.

[41] A. Petzold, L. T. Sharpe, and G. Keir, "Spectrophotometry for cerebrospinal fluid pigment analysis," Neurocritical Care, vol. 4, no. 2, pp. 153-162, 2006.

[42] R. Fishman, Cerebrospinal Fluid in Disease of the Nervous System, Saunders, Philadelphia, Pa, USA, 1980.

[43] J.-S. Youl, V. Gelfanova, M. D. Knierman, F. A. Witzmann, M. Wang, and J. E. Hale, "The impact of blood contamination on the proteome of cerebrospinal fluid," Proteomics, vol. 5, no. 1, pp. 290-296, 2005.
[44] A. L. Biere, B. Ostaszewski, E. R. Stimson, B. T. Hyman, J. E. Maggio, and D. J. Selkoe, "Amyloid $\beta$-peptide is transported on lipoproteins and albumin in human plasma," Journal of Biological Chemistry, vol. 271, no. 51, pp. 32916-32922, 1996.

[45] S. R. Hughes, O. Khorkova, S. Goyal et al., " $\alpha 2$-macroglobulin associates with $\beta$-amyloid peptide and prevents fibril formation," Proceedings of the National Academy of Sciences of the United States of America, vol. 95, no. 6, pp. 3275-3280, 1998.

[46] A. Sagare, R. Deane, R. D. Bell et al., "Clearance of amyloid- $\beta$ by circulating lipoprotein receptors," Nature Medicine, vol. 13, no. 9, pp. 1029-1031, 2007.

[47] N. Le Bastard, L. Aerts, J. Leurs, W. Blomme, P. P. De Deyn, and S. Engelborghs, "No correlation between time-linked plasma and CSF A $\beta$ levels," Neurochemistry International, vol. 55, no. 8, pp. 820-825, 2009.

[48] H. Zetterberg, "Is plasma amyloid- $\beta$ a reliable biomarker for Alzheimer's disease?" Recent Patents on CNS Drug Discovery, vol. 3, no. 2, pp. 109-111, 2008.

[49] M. Sjögren, M. Gisslén, E. Vanmechelen, and K. Blennow, "Low cerebrospinal fluid $\beta$-amyloid 42 in patients with acute bacterial meningitis and normalization after treatment," Neuroscience Letters, vol. 314, no. 1-2, pp. 33-36, 2001.

[50] R. J. Bateman, G. Wen, J. C. Morris, and D. M. Holtzman, "Fluctuations of CSF amyloid- $\beta$ levels: implications for a diagnostic and therapeutic biomarker," Neurology, vol. 68, no. 9, pp. 666-669, 2007.

[51] D. M. Walsh, B. P. Tseng, R. E. Rydel, M. B. Podlisny, and D. J. Selkoe, "The oligomerization of amyloid $\beta$-protein begins intracellularly in cells derived from human brain," Biochemistry, vol. 39, no. 35, pp. 10831-10839, 2000.

[52] C. Fabrizi, R. Businaro, G. M. Lauro, and L. Fumagalli, "Role of alpha2-macroglobulin in regulating amyloid beta-protein neurotoxicity: protective or detrimental factor?" Journal of Neurochemistry, vol. 78, pp. 406-412, 2001.

[53] W. J. Strittmatter, A. M. Saunders, D. Schmechel et al., "Apolipoprotein E: high-avidity binding to $\beta$-amyloid and increased frequency of type 4 allele in late-onset familial Alzheimer disease," Proceedings of the National Academy of Sciences of the United States of America, vol. 90, no. 5, pp. 19771981, 1993.

[54] J. Ghiso, E. Matsubara, A. Koudinov et al., "The cerebrospinalfluid soluble form of Alzheimer's amyloid beta is complexed to SP-40,40 (apolipoprotein J), an inhibitor of the complement membrane-attack complex," Biochemical Journal, vol. 293, no. 1, pp. 27-30, 1993.

[55] E. Matsubara, B. Frangione, and J. Ghiso, "Characterization of apolipoprotein J-Alzheimer's A $\beta$ interaction," Journal of Biological Chemistry, vol. 270, no. 13, pp. 7563-7567, 1995.

[56] J. Herz and P. Marschang, "Coaxing the LDL receptor family into the fold," Cell, vol. 112, no. 3, pp. 289-292, 2003.

[57] A. L. Schwarzman, L. Gregori, M. P. Vitek et al., "Transthyretin sequesters amyloid $\beta$ protein and prevents amyloid formation," Proceedings of the National Academy of Sciences of the United States of America, vol. 91, no. 18, pp. 8368-8372, 1994.

[58] M. A. Pericak-Vance, J. L. Bebout, P. C. Gaskell Jr. et al., "Linkage studies in familial Alzheimer disease: evidence for chromosome 19 linkage," American Journal of Human Genetics, vol. 48, no. 6, pp. 1034-1050, 1991.

[59] J. Kuusisto, K. Koivisto, K. Kervinen et al., "Association of apolipoprotein E phenotypes with late onset Alzheimer's disease: population based study," British Medical Journal, vol. 309, no. 6955, pp. 636-638, 1994. 
[60] T. Tokuda, M. Calero, E. Matsubara et al., "Lipidation of apolipoprotein $\mathrm{E}$ influences its isoform-specific interaction with Alzheimer's amyloid $\beta$ peptides," Biochemical Journal, vol. 348, no. 2, pp. 359-365, 2000.

[61] J. Wiltfang, H. Esselmann, M. Bibl et al., "Highly conserved and disease-specific patterns of carboxyterminally truncated A $\beta$ peptides $1-37 / 38 / 39$ in addition to $1-40 / 42$ in Alzheimer's disease and in patients with chronic neuroinflammation," Journal of Neurochemistry, vol. 81, no. 3, pp. 481-496, 2002.

[62] M. Bibl, H. Esselmann, M. Otto et al., "Cerebrospinal fluid amyloid $\beta$ peptide patterns in Alzheimer's disease patients and nondemented controls depend on sample pretreatment: indication of carrier-mediated epitope masking of amyloid $\beta$ peptides," Electrophoresis, vol. 25, no. 17, pp. 2912-2918, 2004.

[63] P. Lewczuk, G. Beck, O. Ganslandt et al., "International quality control survey of neurochemical dementia diagnostics," Neuroscience Letters, vol. 409, no. 1, pp. 1-4, 2006.

[64] N. A. Verwey, W. M. van der Flier, K. Blennow et al., "A worldwide multicentre comparison of assays for cerebrospinal fluid biomarkers in Alzheimer's disease," Annals of Clinical Biochemistry, vol. 46, no. 3, pp. 235-240, 2009. 


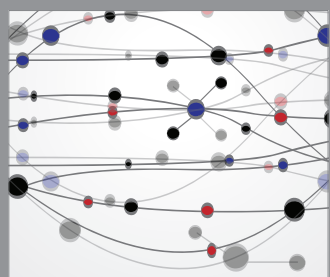

The Scientific World Journal
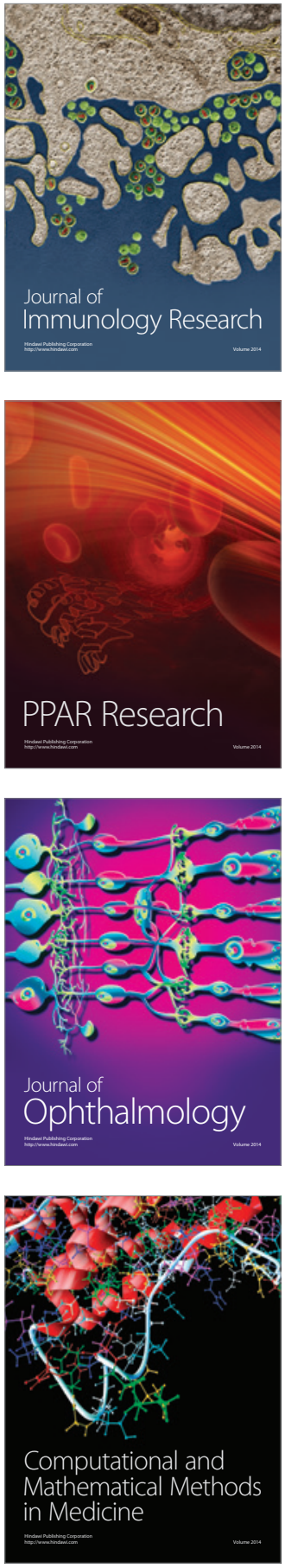

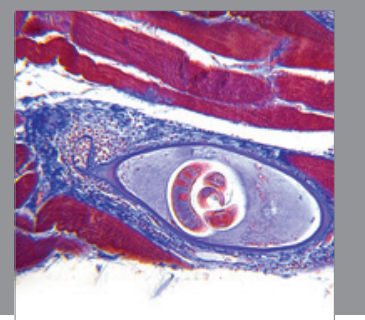

Gastroenterology

Research and Practice
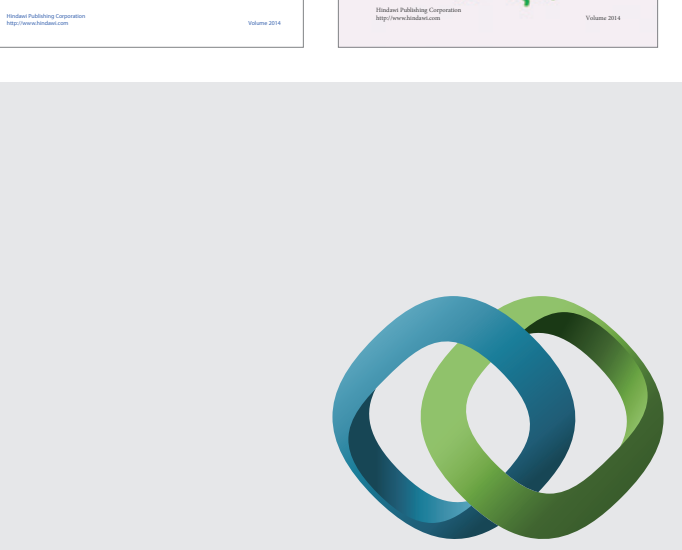

\section{Hindawi}

Submit your manuscripts at

http://www.hindawi.com
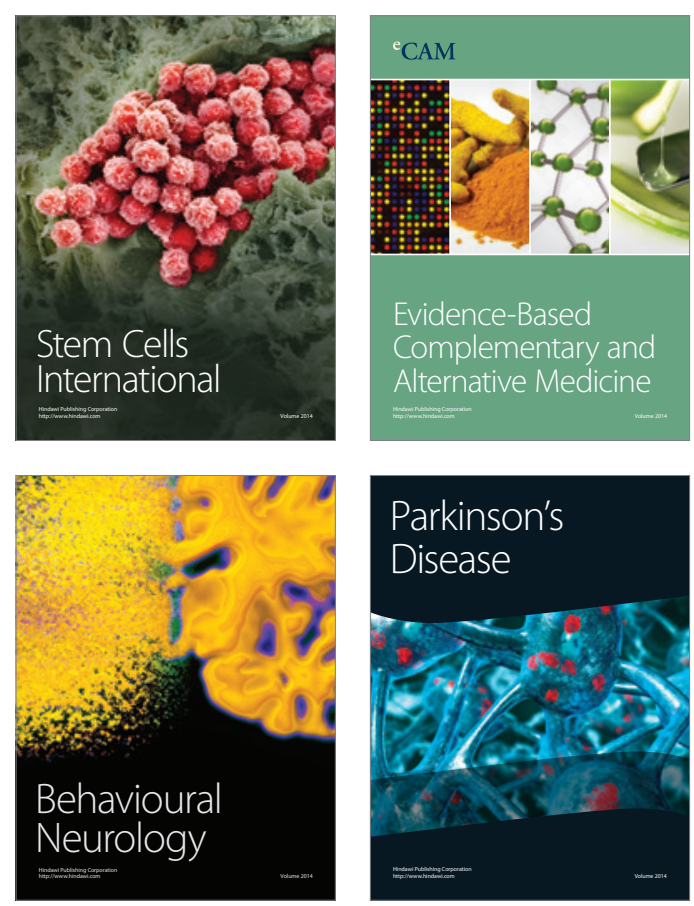

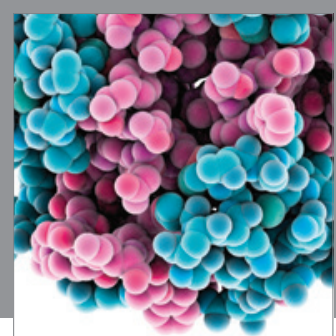

Journal of
Diabetes Research

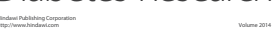

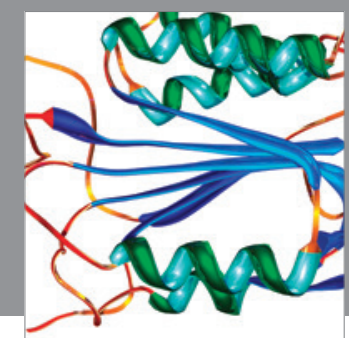

Disease Markers
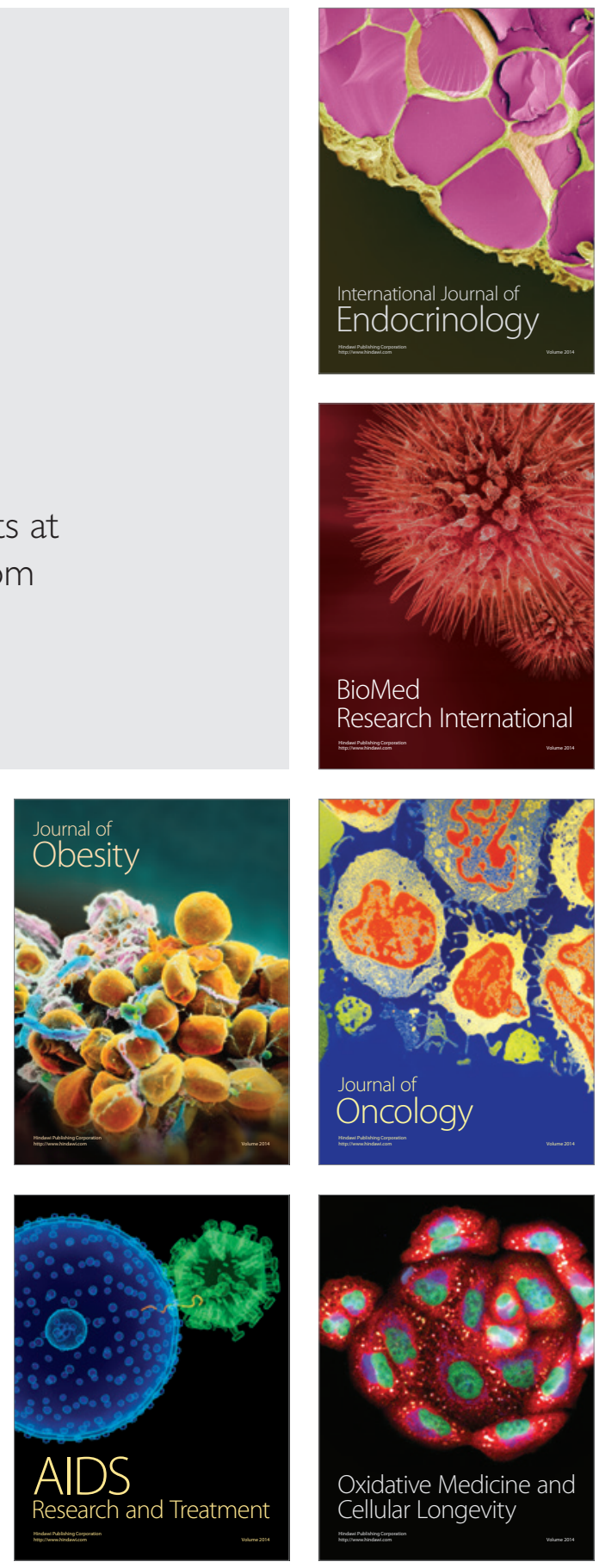